\title{
Cultura popular: as inscrições amorosas da Pompéia Romana
}

\author{
LOURDES M. G. C. FEITOSA \\ UNICAMP \\ Núcleo de Estudos Estratégicos (NEE)
}

\begin{abstract}
RESUMO: Neste artigo discute-se o significado do conceito de cultura e como diversas experiências culturais são construidas no interior de cada sociedade. Para o estudo da Antigũidade romana, as inscrições parietais significam importantes fontes para a reflexão sobre a cultura popular, particularmente de Pompéia. Por meio da análise de alguns grafites, questiona-se a idéia de absorção cultural e como as representações passam pelo crivo e valor popular.
\end{abstract}

PALAVRAS-CHAVE: cultura popular; inscriçōes parietais; representaçōes do amor.

\section{Conceituando cultura popular}

A partir do século XIX, muitas reflexões e idéias têm sido manifestadas sobre o conceito de "cultura popular" sem que se tenha chegado a algum consenso. O termo cultura popular passa a ser registrado no início do século XIX, na Europa, e embora questionando o modelo unívoco de cultura, as distinções atribuídas à expressão marcaram, entre outras, a noção de uma reprodução "imperfeita" e "deteriorada" da cultura erudita, ou ainda, de uma produção própria, porém isolada, restrita ao campo e ligada a tradições folclóricas de camponeses analfabetos. Assim, convencionou-se denominar cultura erudita, também conhecida como dominante ou superior, aquela conectada com as elites, e cultura popular, inferior ou subalterna, aquela produzida e vivenciada pelo povo'.

Principalmente a partir da segunda metade do século XX, em um contexto de forte crítica ao colonialismo e à dominação de classe, estudos de áreas como Antropologia, História e Arqueologia, passam a questionar o conceito de cultura e suas derivações "cultura inferior ou primitiva" e "cultura superior". Acentuadas críticas são apresentadas à idéia de um centro propagador de cultura, fomentado por grupos dominantes, e à prática de absor-

A ambigüidade e a complexidade que envolvem o termo em sua longa trajetória foram detalhadas por alguns historiadores como pode ser visto em de Certeau, 1995, p. 71, 166; Burke, 1989, introdução; Ginzburg, 1987, p. 17-8 e Funari, 1987, p. 33-5; 1989 e 1993. 
ção, ainda vista como natural, da cultura superior pelos membros das classes "subalternas". Dentre estas vozes, destacamos o estudioso francês Michel de Certeau que, já no início dos anos setenta, tecia duras crítica à generalização do padrão cultural das elites francesas como o modelo digno de conhecimento e perpetuação pela sociedade, de maneira que "os ineptos são excluídos não somente de uma cultura, mas da cultura (uma vez que o sistema que os elimina de uma "instrução" os rouba também de suas tradições próprias)..." (de Certeau, 1995, p. 167; grifos do autor).

Considerar apenas uma cultura em uma sociedade indica a aceitação do conceito de cultura estabelecido pelos grupos dominantes, que reconhecem, como legítimos e verdadeiros, apenas os seus próprios valores culturais. Por isso, localizar socialmente os discursos, estabelecendo o seu ethos de classe, é tarefa importante para não se generalizar conceitos e valores de uma classe como os verdadeiros e únicos em toda uma sociedade ${ }^{3}$.

Com o deslocamento do enfoque de uma para várias culturas, dentro de uma mesma sociedade, abre-se a possibilidade de valorizar o universo concebido e articulado pelos diferentes grupos que se estabelecem em seu interior. Dessa ótica, pode-se afirmar que cultura: "é tudo que resulta do trabalho e da elaboração humanos... todos são difusores do saber e exercem um papel ativo na organização do mundo social, em termos econômicos, políticos e culturais" (Funari, 1989, p. 12-3), já que "cultura não consiste em receber, mas em realizar o ato pelo qual cada um marca aquilo que os outros lhe dão para viver e pensar" (de Certeau, 1995, p. 143. Grifo do autor).

Dessa perspectiva, a produção cultural de uma sociedade passa a ser fruto da ação e manifestação de todos os seus indivíduos, independentemente do lugar social ocupado por cada um, o que não significa dizer que produzam a mesma coisa ou que algumas sejam mais valiosas e preponderantes que outras. Também, é certa a impossibilidade de se estabelecer, com precisão, os limites dos aspectos culturais de um grupo com relação a outros grupos, da mesma maneira que não é razoável considerá-las estática e desarticulada entre si, e compostas em suas próprias "totalidades". Assim, a designação de cultura como uma coleção de elementos e tradições valorosas e imutáveis, sejam elas das elites ou dos populares, não tem mais como ser sustentada. Isto porque estas práticas culturais redefinem-se diariamente na dinâmica do cotidiano, nas experiências de integração, conflitos e contradições ocorridas entre elas na organização social e em seus contatos com culturas externas ${ }^{4}$. Críticas são apresentadas às três idéias vinculadas, comumente, ao conceito de cultura, quais sejam, de

2 Cf., entre outros, de Certeau, 1995 (publicação francesa de 1973); Mezhuiev, 1980; Ginzburg, 1987; Funari, 1989; Burke, 1989; Davis, 1990; Arantes, 1995 e Horsfall, 1996.

3 Como salienta Foucault, é necessário saber quem fala, de onde fala e por quê fala, pois qualquer argumento possui uma conotação política e realça um caráter de classe (Foucault, 1996, p. 52 3). Também Michel de Certeau opõe-se à idéia de uma produção sócio-cultural unívoca em uma sociedade, pois acredita que "o lugar de onde se fala, no interior de uma sociedade, emerge silenciosamente no discurso e reproduz-se no nível do conteúdo intelectual, com o ressurgimento de um modelo totalitário. Com efeito, a cultura no singular traduz o singular de um meio". Cf. de Certeau, 1995, p. 227.

4 Interessantes discussões sobre esta questão podem ser encontradas em Jones, 1997 e Funari, Hall, Jones, 1999. 
que em uma sociedade existe uma cultura; que $a$ cultura é o que é produzido pelos grupos dominantes e, por fim, que a cultura deve ser entendida como um conjunto de tradições consolidadas e hermeticamente transmitidas.

É dessa perspectiva de se olhar para cultura que este trabalho apresenta, a seguir, um histórico sobre o uso da documentação epigráfica para o estudo da Antigũidade, em particular, dos grafites, para uma análise de aspectos da cultura popular em Pompéia.

\section{O uso das inscrições romanas como documento histórico}

Intensificou-se, nos últimos anos, em diferentes campos das Ciências Humanas, a utilização de fontes diversas, além da usual documentação literária, para a ampliação de informações sobre a organização social de sociedades passadas. A própria releitura de fontes literárias, agora analisada como uma representação específica das elites, e o uso de outras evidências históricas como as fontes epigráficas, arqueológicas, iconográficas, entre outras, têm trazido valiosas contribuições para este processo de revisão e ampliação das temáticas discutidas na Histórica.

Pode caracterizar-se a Epigrafia como a parte da Paleografia que estuda as inscrições, incluindo sua decifração, datação e interpretação. A palavra "inscrição" tem sua origem no vocábulo latino inscriptio - ação de escrever sobre - e é utilizada em tempos modernos para caracterizar um texto entalhado, gravado, traçado ou ainda estampado sobre superfícies duráveis como pedras, metais, cerâmicas, telhas, vidros, reboco de muros, mosaicos tesserae (Keppie, 1991, p. 10; Bodel, 2001, p. 2).

Dentre as inscrições romanas encontradas, distinguem-se:

- as monumentais, gravadas ou esculpidas em letras maiúscula em monumentos, tumbas funerárias, edifícios públicos, dentre outros; usadas, principalmente, para divulgação de decretos oficiais, datas comemorativas ou fins honoríficos.

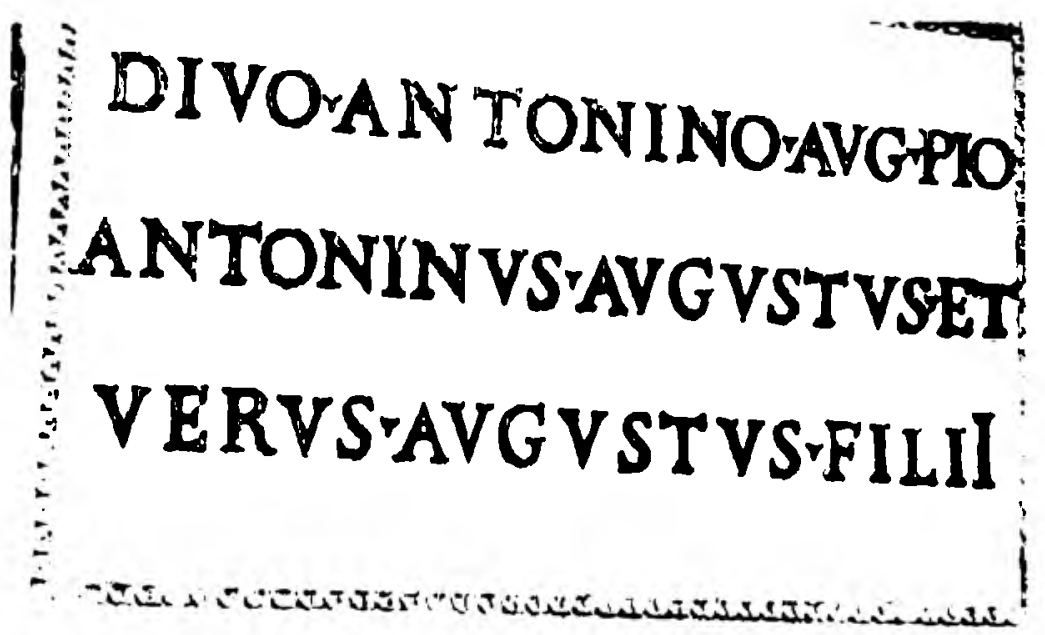

Fig. 1: Coluna de bronze de Antonino Pio. Roma, 161-169 d.C.

(Fonte: Keppie, 1991, p. 26) 
- as comuns, escritas em letras cursivas, utilizadas pelo povo para registros de fatos do cotidiano.

Estas inscrições em letras comuns são chamadas de grafites, derivada de graphium, instrumento utilizado para o seu desenho. Este objeto possuía a ponta dura, permitindo que as pessoas delineassem, com alguma facilidade, o sulco no formato das letras desejadas. Este traçado sobre as paredes, chamado em latim de graphio inscripta, era a maneira mais comum e freqüente das pessoas se expressarem.

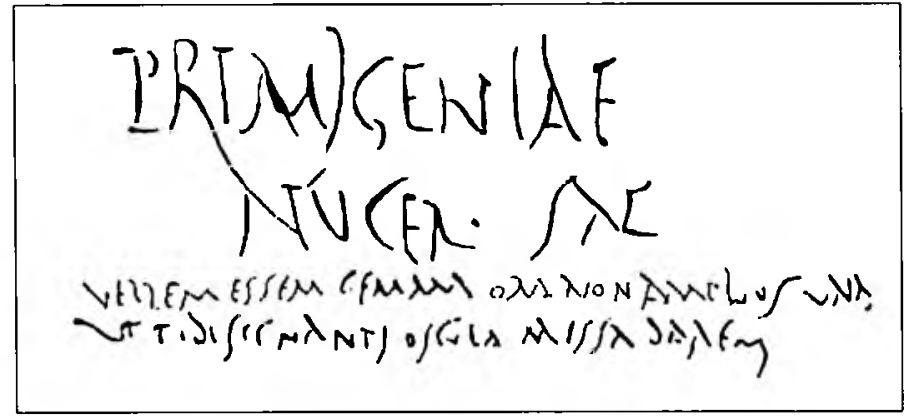

Fig. 2: Imagem de um grafite CIL, IV, 10241

Também eram usados os grafites pintados - tituli picti -, mas em escala bem menor.

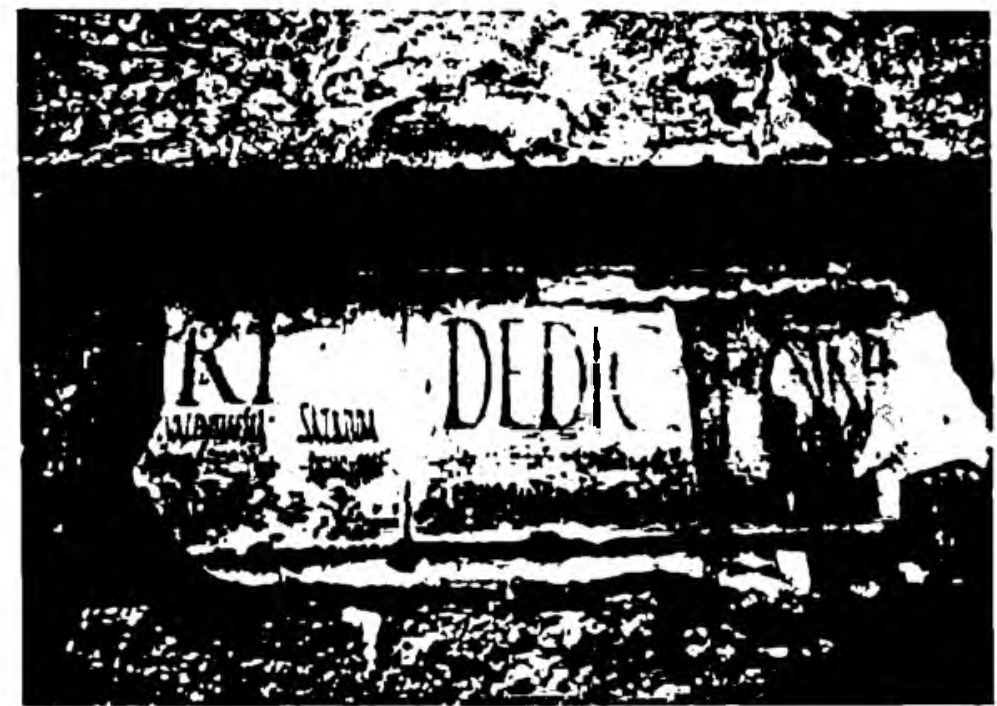

Fig. 3: Grafites pintados (tituli picti) em uma das paredes de Pompéia (foto da autora)

As inscrições de sociedades antigas passaram a ser abundantemente encontradas nas escavações arqueológicas, a partir do século XVIII, estimulando o ritmo destas escavações e a própria consolidação da Arqueologia como área científica. 
No mundo romano, a grande quantidade de grafites obtida em diferentes extensões de seu domínio, instigou a organização, em 1847, de um grupo de estudo, coordenado pelo pesquisador alemão Theodor Mommsen, preocupado em catalogar e publicar as inscrições latinas oriundas de todas as partes da sociedade romana (Keppie, 1991, p. 36). Desta maneira foi originado o Corpus Inscriptionum Latinarum, mais comumente conhecido por CIL.

Ficou estabelecido o critério geográfico para a organização deste manancial documental, tendo sido atribuídos números para as diferentes regiões como, por exemplo, CIL II Espanha, CIL VI - Roma. Algumas poucas exceções deste critério regional ficaram para a coleção de registros sobre a morte de César - publicadas no volume I, ou as inscrições parietais sobre Pompéia, Herculano e outras cidades da região vesuviana - volume IV (Bodel, 2001, p. 7, 159). Muitos volumes do CIL foram publicados entre os anos de 1870 a 1890, diversos deles revisados e complementados em suplementos posteriores. Trabalho que continua a ser realizado e agora conta com versões eletrônicas disponibilizadas em páginas da web tais como: http://www.bbaw.de/vh/cil/index.html ou http://www.uni-heidelberg.de/ institute/sonst/adw/edh.

As inscrições vesuvianas têm sido abundantemente encontradas em muros, paredes externas e internas de edifícios públicos, tabernas, locais de trabalho, habitações, ou seja, em quase todos os espaços disponíveis nas paredes da cidade até então escavadas. Como sugere Cartelle (1981, p. 81), parece razoável não terem sido achados livros nas cidades vesuvianas, na medida que estes não poderiam suportar as altas temperaturas, as cinzas e os lapilli ardentes que os teriam coberto. Situação semelhante aos livros parece ter ocorrido com as tabuletas de cera, dispositivo usual para escrita e leitura, das quais se pode ter alguma idéia a partir daquelas encontradas em cofre de madeira pertencente ao banqueiro L. Caecilius Iucundus. A cera estava derretida, mas como a ponta do graphium havia alcançado a madeira que ficava por trás, foi possível reconstruir parte das informações, publicadas no CIL, Suplemento I, referido anteriormente ${ }^{5}$. Entretanto, o volume de grafites e os diferentes graus de conhecimento do latim expresso em sua grafia, são evidências da prática de escrita e da leitura e, portanto, da existência do alfabetismo na cidade de Pompéia ${ }^{6}$.

Alguns aspectos ajudaram a estabelecer o período em que estes grafites foram escritos. Como Pompéia foi soterrada no ano de 79 d.C., esta é a data limite para a sua realização. Por outro lado, considerando o forte abalo sísmico que a cidade sofrera em 62 , fazendo com que muitas inscrições fossem destruídas junto às construções derrubadas, a usual limpeza das áreas de publicidade, assim como as condições climáticas que têm interferido na preservação ou destruição dos grafites ${ }^{7}$, estima-se que a grande maioria destes ícones tenha sido produzida nos últimos vinte anos da cidade. Precisar o período em que foram escritas é um aspecto diferenciador entre estas inscrições comuns e outras poucas do mesmo gênero,

5 Referência ao seu uso ver, também, em CIL, IV, 1796.

6 Sobre esta questão conferir Väanänen, 1937, p. 15; Gigante, 1979, p. 37 e 41; Funari, 1989, p. 28; Franklin, 1991, p. 82 e Varone, 1994, p. 9.

7 A ação atmosférica sobre os grafites tem sido verificada nas regiões escavadas, exigindo cuidados especiais para o não desaparecimento. 
encontradas em diversas partes do mundo romano e que são, em geral, muito difíceis de serem datadas (Väănänen, 1937, p. 19).

A ação dos grafiteiros era tão intensa e freqüente que mesmo com a atuação dos dealbatores, trabalhadores que tinham a finalidade de limpar as paredes, muitas são as inscrições descobertas em escavações, como mencionado anteriormente. $\mathrm{O}$ dealbator atuava para apagar, das paredes, velhas notícias, mensagens indesejáveis ou mesmo para deixá-las limpas. Parte destes novos espaços era utilizado com recados "oficiais", entendidos como anúncios de venda de produtos, propaganda de espetáculos ou cartazes eleitorais, por exemplo, escrito, via encomenda, por trabalhadores pagos - os scriptores ${ }^{8}$. Contudo, de todas as inscrições catalogadas, a imensa maioria corresponde àquelas registradas pelo autor de próprio punho.

Estes grafites têm suscitado grande interesse paleográfico, lingüístico e literário, por diversos aspectos como, por representarem umas das raras escritas cursivas da Antigüidade $^{9}$; permitirem analisar os processos de transformações ocorridos no latim popular e no erudito (Cartelle, 1981, p. 83) e pela difusão da cultura literária fora dos círculos das elites ${ }^{10}$. Entretanto, aqui, o interesse é fundamentalmente em seu caráter histórico-cultural. E por meio deste precioso testemunho epigráfico que se consegue conhecer aspectos da vida, dos costumes e do sentimento amoroso destes pompeianos.

A preservação da estrutura da cidade e de seus objetos de uso cotidiano leva ao conhecimento de sua vida material e os grafites completam os dados com informações que revelam opiniões, desejos, experiências e sentimentos que saem diretamente da alma das pessoas para os muros da cidade. Assim, a possibilidade de analisar esta rica documentação epigráfica faz de Pompéia uma fonte ímpar para o estudo das relações vivenciadas entre homens e mulheres populares, que habitaram esta colônia romana, e das quais alguns aspectos são apresentados a seguir.

\section{Manifestações do sentimento amoroso}

Os muros de Pompéia demonstram o quanto era comum mulheres e homens registrarem a felicidade de um amor compartilhado, a tristeza pela distância da amada, os ciúmes, os lamentos e as decepções por causa de um relacionamento rompido. Nestas muitas manifestações, encontram-se traços da inserção da cidade em um contexto mais amplo da sociedade romana. Além da prevalência do argumento historiográfico contemporâneo a favor da participação econômica de Pompéia no comércio interprovincial, exportando e importando

8 Conferir menções a estes trabalhadores em CIL, IV 222, 230, 1190 e 3529.

9 Outros exemplos de letras cursivas são encontrados nas escritas hierática e demótica egípcia, nas tabuletas de cera pompeianas e em registros esparsos descobertos na região do império romano.

10 Por meio da análise de Gigante, é possível verificar o grande número de referências da literatura grega, helenística e romana nos grafites, confirmando a afinidade dos populares pompeianos com a leitura e a escrita. Cf. Gigante, 1979, p. 26. 
produtos ${ }^{11}$, também é possível verificar a influência literária épica, elegíaca e dramática de Roma, mas também da cultura grega e helenística, principalmente nos epigramas eróticos, nestas representações do sentimento afetivo (Gigante, 1979, p. 37). Muitas passagens de autores como Homero, Tiburtino, Virgílio, Ovídio, Catulo, Lucrécio são atestadas nos grafites.

Este contato e aprendizado literário poderia ter ocorrido tanto por meio da escola, como por meios pedagógicos alternativos, principalmente para o conhecimento da língua e cultura grega, como o contato com imigrantes, com o comércio, prestação do serviço militar, além das representações teatrais e da atuação dos circulatores, pessoas que promoviam entretenimentos itinerantes, com funções de cantar, declamar poesias ou ler trechos de livros (Horsfall, 1996, p. 28, 47).

Uma questão a ser discutida diante desta manifestação popular, que por vezes menciona obras da literatura aristocrática, é se isto caracterizaria uma absorção e submissão intelectual à cultura erudita. A análise de algumas inscrições parietais amorosas de Pompéia possibilita refletir sobre o assunto.

Muitas das inscrições encontradas são de menções rápidas e suscitadas diretamente do coração, como este grafite que, mesmo sem a assinatura de seu autor, não deixou no anonimato o seu amor por uma Taine: Dulcis amor perias eta (pro ita). Taine bene amo dulcissima, mea dulc (CIL, IV, 8137) [Oxalá pereça, doce amor. Amo tanto a Taine minha dulcíssima amada] ${ }^{12}$, o mesmo fez Marcos: Marcus Spedusa amat (CIL, IV, 7086) [Marcos ama Spedusa]. E algum rival de Marcelo provavelmente tenha sido o autor deste registro: Marcellus Praenestinam amat, et non curatur (CIL, IV, 7679) [Marcelo ama Prenestina, e não é correspondido].

Um outro apaixonado repetiu os versos de Horácio para exaltar aqueles que amavam e repreender os que representavam empecilhos aos amantes: (Quis) quis amat ualeat pereat qui nescit amare. Bis tanto pereat quisquis amare uetat (CIL, IV, 4091) [Viva quem ama, que morra quem não sabe amar! Duas vezes morra quem proíbe o amor $]^{13}$. Idéia não compartilhada pela pessoa que opinou sobre isso, talvez por estar sofrendo a dor de uma desilusão amorosa: Quisquis amat pereat (CIL, IV, 4659) [Morra quem quer que ame!]. Ainda uma outra reproduziu o poema de Propércio para expressar semelhante decepção: Quisquis amat calidis non debet fontibus uti, nam nemo flammas ustus amare potest (CIL, IV, 1898) [Qualquer um que ama não deve se banhar em fontes quentes, pois ninguém que esteja escaldado pode amar as chamas].

Catulo serviu de inspiração a uma jovem que havia amado e estado "nas nuvens" pela felicidade de seu amor e que, depois, chorava o abandono de seu querido: $O$ utinam liceat collo complexa tenere. Braciola et teneris oscula ferre labe(l)lis. I nunc, uentis tua gaudia, pupula, crede. Crede mihi, leuis est natura uirorum. Saepe ego cu(m) media

"Conferir, entre outros autores, Della Corte, 1954; Étienne, 1967; Guarinello, 1985; Funari, 1989 e Laurence, 1994.

12 Proposta de interpretação de Cartelle, 1981, p. 97.

${ }^{13}$ As indicações sobre as inspirações literárias apresentadas nos grafites são de Gigante, 1979. As traduções das inscrições são da autora, salvo quando indicado de outra maneira. 
uigilare(m) perdita nocte. Haec mecum medita(n)s: multos Fortuna quos supstulit alte, hos modo proiectos subito praecipitesque premit. Sic Venus ut subito coiunxit corpora amantum, Diuidit lux et se (paries quid?) (CIL, IV, 5296) [Oh, se fosse possível manter meus braços enlaçados ao teu pescoço e levar meus beijos aos teus doces lábios! Mas agora vai, menininha, entrega teus prazeres ao vento. Creia em mim, inconstante é a natureza dos varões. Muitas vezes, eu, apaixonada, na madrugada, em vigília, pensava comigo mesma: muitos alçados pela Fortuna ao topo, foram, súbita e precipitadamente, rebaixados. Assim, Vênus, tão logo junte os corpos dos amantes, divide a luz.... $]^{14}$.

A manifestação de lamento deste poema foi, segundo Gigante, influenciada pelo modelo da elegia amorosa romana; entretanto, a característica popularesca e uma certa simplicidade de estilo foram mantidas pela compositora (Gigante, 1979, p. 212). Tecnicamente "defeituoso", segundo a regra literária erudita, estes versos expressam a criatividade e fluidez de uma composição cuja mensagem revela-se espontânea e direta, em harmonia com a linguagem popular em que foi criada.

Um outro aspecto muito significativo nos versos pompeianos é a representação feita da deusa Vênus. O próprio nome de Colonia Cornelia Veneria Pompeiorum atribuído a Pompéia no momento em que foi anexada por Sila ao império Romano, indica a importância de Vênus como deusa protetora da cidade e de seus amantes. $O$ modelo em pintura mais famoso (Vênus em uma concha) foi encontrado no peristilo de uma casa de Pompéia (II, 3, 3), de uma família aristocrática.

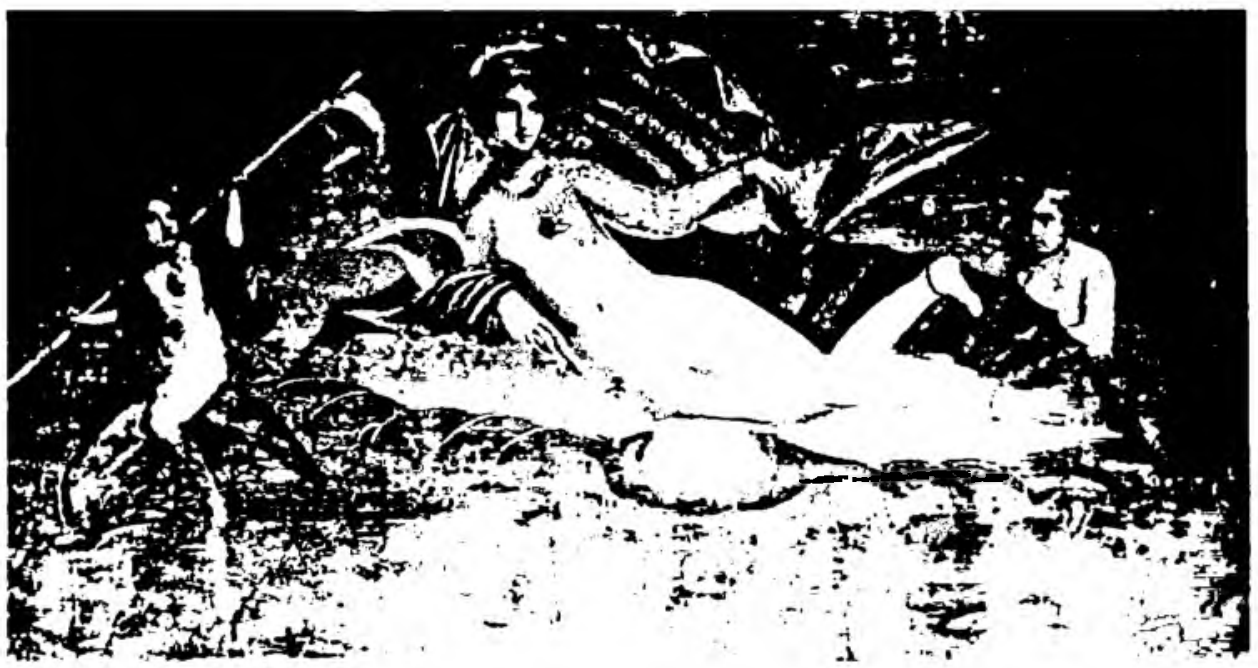

Figura 4.1: Vênus em uma concha (De Carolis, 2000: 36)

Como pode ser visto na figura, a deusa é representada com um formoso corpo e ricamente adornada com jóias, em uma pintura em quarto estilo sob inspiração helenística ${ }^{15}$.

14 Nos versos finais deste poema segue-se a proposta de interpretação de Funari, 1995, p. 183.

15 O estilo iconográfico da época helenística é repetido com freqüência nas pinturas, mosaicos e esculturas de Pompéia, como pode ser observado em De Carolis, 2000. 
Bela, perfeita, rica e soberba. Os grafites populares, entretanto, mostram uma interpretação particular de Vênus. Trata-se de uma deusa presente no cotidiano destas pessoas, próxima de seus pedidos e aflições: Sei quid amor ualeat nostei, sei te hominem scis, commiseresce mei, da ueniam ut ueniam. Flos Veneris mihi de... (CIL, IV, 4971) [Se conheces a força do amor, e a natureza humana, tenha pena de mim, me faças o favor de me conceder os teus favores. Flor de Vênus, para mim...], e identificada às garotas reais deste grupo social: (Non) ego tamcuro Venerem de marmorii, factam s... carmin... (CIL, IV, 3691) [Eu não me preocupo, em meus versos, por uma Vênus feita de mármore, mas por uma de carne e osso...], ou ainda: Si quis non uidi( $t$ ) Venerem quam na... pupa $(m)$ mea $(m)$ aspiciat talis et e... (CIL, IV, 6842) [Se tem alguém que não viu a Vênus que pintou Apeles, que olhe a minha garota: é tão bonita quanto ela!]

É a ela, a responsável pela proteção dos amantes e de seu bom convívio, que são direcionadas as lamúrias de um coração partido e inconformado com a dor de uma desilusão amorosa: Quisquis amat ueniat; Veneri uolo frangere costas. Fustibus et lumbos debilitare deae: si pot( is) illa mihi tenerum pertundere pectus, quit ego non possim caput illae frangere fuste? (CIL, IV, 1824) [A todos os que amam, permissão. Quero quebrar as costas de Vênus com o bastão e deixar o seu lombo machucado. Se ela pode trespassar meu terno coração, por que não poderia eu romper sua cabeça com um bordão?]. Estas inscrições são exemplos do sentido que Vênus toma entre populares de Pompéia, uma deusa próxima à condição de humanidade, a companheira que recebe os sinceros sentimentos das almas em júbilo ou tristeza, experimentados em cada vivência de amor.

\section{Considerações finais}

Alguns aspectos podem ser realçados nesta reflexão. O primeiro é que, no interior de cada sociedade, constituem-se diferentes experiências culturais, frutos das práticas cotidianas, dos contatos, influências e embates originados entre os grupos sociais e das mais variadas respostas apresentadas.

Sobre os valores culturais populares da Pompéia Romana do século I d.C, as inscrições parietais caracterizam-se como raros e importantes vestígios destes grupos. Neste artigo, são destacadas algumas leituras amorosas apresentadas em grafites e mostrado, onde se identifica um contato cultural com obras aristocráticas, uma releitura ao gosto e fluidez popular. Também, como símbolos gerais, aqui em particular a deusa Vênus, recebem diferentes representações a partir das concepções e valores considerados por cada grupo.

\section{Referências Bibliográficas}

\section{Documentação Antiga:}

CIL - Corpus Inscriptionum Latinarum. v. IV. Berlim: Akademie Verlag, desde 1863. 


\section{Dicionários:}

ERNOUT, A. Dictionnaire Etymologique de la Langue Latine. Paris: Livraria C. Klicksieck. 1967.

FERREIRA, A. G. Dicionário de Latim - Português. Portugal: Porto, s/d.

\section{Textos Epigráficos:}

BODEL, J. (Ed.). Epigraphic Evidence. Ancient history from inscriptions. London/New York: Routledge, 2001.

CARTElLE, E. M. Priapeos; grafitos amatorios Pompeyanos; la valada de la fiesta de Venus; el concúbito de Marte y Venus; centón nupcial. Madrid: Biblioteca clásica Gredos, 1981.

CORBIER, P. L'epigraphie latine. Paris: Sedes, 1998.

DELLA CORTE, M. Case ed abitanti di Pompei. Roma: L’Erma, 1954.

GIGANTE, M. Civiltà delle forme letterarie nell'antica Pompei. Roma: Bibliopolis, 1979. IRELAND, R. Epigraphy. In: HENIG, M. (Ed.). A handbook of Roman Art. Ithaca/New York: Cornell University Press, 1983, p. 220-33

KEPPIE, L. Understanding Roman inscriptions. Baltimore: John Hopkins University Press, 1991.

VÄ̈̈NÄNEN, V. Le latin vulgaire des inscriptions pompéienes. Helsinki: Annales Academiae Scientiarum Fennicae, 1937.

VARONE, A. Erotica pompeiana. Iscrizioni d'amore sui muri di Pompei. Roma: L'Erma, 1994.

\section{Textos Contemporâneos:}

ARANTES, A. A. O que é cultura popular. São Paulo: Brasiliense, 1995.

BURKE, P. Cultura popular na Idade Moderna. Tradução de Denise Bottmann. São Paulo: Companhia das Letras, 1989.

DAVIS, N. Culturas do povo. Sociedade e cultura no início da França moderna. Tradução de Mariza Corrêa. Rio de Janeiro: Paz e Terra, 1990.

DE CAROLIS, E. Dei ed eroi nella pittura pompeiana. Roma: L'Erma, 2000.

DE CERTEAU, M. A cultura no plural. Tradução de Enid A. Dobránszky. Campinas: Papirus, 1995. Publicação francesa de 1973.

DE CERTEAU, M. A invenção do cotidiano: 1. Artes de fazer. Tradução de Ephraim Ferreira Alves. 4. ed. Petrópolis: Vozes, 1999.

DE ROBERTIS, F. M. Storia sociale di Roma. Le classi inferiori. Roma: L'Erma, 1981.

ETIENNE, R. La vida cotidiana em Pompeya. Tradución de Jose A. Miguel. Madrid: Aguilar, 1971. (Publicação francesa de 1967)

FOUCAULT, M. A ordem do discurso. Tradução de Laura F. Sampaio. São Paulo: Loyola, 1996. 
FRANKLIN, Jr. J. L. Pompeis difficile est. Studies in the political life of Imperial Pompeii. Michigan: Ann Arbor, 2001.

FUNARI, P. P. A. Cultura popular na Antigüidade clássica. São Paulo: Contexto, 1989.

FUNARI, P. P. A. Cultura(s) dominante(s) e cultura(s) subalterna(s) em Pompéia: da vertical da cidade ao horizonte do possível. Revista Brasileira de História, v. 7, n. 13, p. 3348, set/86-fev/87. São Paulo: 1987.

FUNARI, P. P. A. El caráter popular de la caricatura pompeyana. Gerión, n. 11, p. 153-73. Madrid: 1993.

FUNARI, P. P. A; HALL, M.; JONES, S. Historical Archaeology. Back from the edge. London/New York: Routledge, 1999.

GUARINELLO, N. L. Análise espacial de um edifício rural de época romana - a Villa da localidade de Setti Termini no ager pompeianus. Dédalo, n²4, p. 207-34, 1985.

GINZBURG, C. $O$ queijo e os vermes: o cotidiano e as idéias de um moleiro perseguido pela Inquisição. Tradução de Betania Amoroso. São Paulo: Companhia das Letras, 1987.

HORSFALL, N. La cultura della plebs romana. Barcelona: PPU, 1996.

JONES, S. The Archaeology of Ethnicity. Constructing identities in the past and present. London: Routledge, 1997.

LAURENCE, R. Roman Pompeii. Space and society. London: Routledge, 1994.

MEZHUIEV, V. La cultura y la Historia. Moscou: Progresso, 1980.

Schiavitù, manumissione e classi dipendenti nel mondo antico. Atti del Colloquio Internazionale su la Schiavitù. Roma: L' Erma, 1981.

TANZER, H. H. The common people of Pompei. A study of the graffiti. Baltimore: The Johns Hopkins Press, 1939.

FEITOSA, Lourdes M. G. C. Popular Culture: the loving inscriptions of the Roman Pompeii. Classica, São Paulo, 15/16, p. 165-175, 2002/2003.

ABSTRACT: This article studies the meaning of "culture" and explores the ways of different cultural experiences constructed inside the society. Roman wall inscriptions are important sources and thorough the study of graffito inscriptions it is possible to think about the role of learned culture in people's ethos. Popular values and feelings are shown in wall inscriptions, translated by the author.

KEYWORDS: popular culture; wall inscriptions; representations of love.

\section{Agradecimentos:}

Meus sinceros agradecimentos a Pedro Paulo A. Funari, a Hércules de A. Feitosa e à FAPESP. As idéias apresentadas são de minha responsabilidade. 